\title{
The Innovative Potential of the Personality of a University Teacher as a Requirement of Time
}

\author{
Tatyana Yu. Artyukhova, ${ }^{1, *}$, Olga A. Kozyreva ${ }^{2}$, Elena P. Fedorova ${ }^{3}$, Elena V. \\ Kirgizova $^{4}$, Oksana A. Benkova ${ }^{1}$, Viktoriya B. Chupina ${ }^{5}$ \\ ${ }^{I}$ Department of Psychology of Development and Consulting Institute of Pedagogy, Psychology and Sociology \\ Siberian Federal University, Krasnoyarsk, Russia \\ ${ }^{2}$ Department Correctional Education, Krasnoyarsk State Pedagogical University named after V. P. Astafyev \\ Krasnoyarsk, Russia \\ ${ }^{3}$ Department of Psychological Anthropology, Institute of Childhood, Moscow State Pedagogical University \\ Moscow, Russia \\ ${ }^{4}$ Department of Higher Mathematics, Computer Science and Natural Sciences, Lesosibirsk Pedagogical Institute - \\ branch of Siberian Federal University, Lesosibirsk, Russia \\ ${ }_{5}^{5}$ Department of Clinical Psychology and Psychotherapy, V.F. Voino-Yasenetsky Krasnoyarsk State Medical University, \\ Krasnoyarsk, Russia \\ ${ }^{*}$ Corresponding author. Email: tartjuchova@mail.ru
}

\begin{abstract}
The introduction of innovations in any sphere of life without a specific person is impossible. The purpose of this article is to consider the innovative potential of a university teacher as a necessary condition for accepting the challenges of our time. The components of the individual's innovative potential are highlighted, and conclusions are drawn about their formation on the basis of the study. The work clarifies the components of innovative potential, presents the results of an empirical study.

Keywords: innovative potential, components of innovative potential, innovativeness, educational environment, personality of the teacher, subjective position, self-development, modern university, university students, challenges of the time
\end{abstract}

\section{INTRODUCTION}

The current stage of development of the higher education system in Russia, starting with its involvement in the Bologna process, is characterized by instability, variability and instability. Over the past two decades, university professors have been involved in the implementation of at least three educational standards. Challenges of the time impose special requirements on the internal and external organization of the university teacher. In changing conditions, it is impossible to act the same way. In this regard, it is important to consider such a personality trait as innovative potential. In the framework of this article, we relied on a system-anthropological (Klochko V.E.), activity and subject-activity approaches (Leontiev A.N., Brushlinsky A.V., Asmolov A.G., etc.).

Starting from the 60 s of the XX century, the category of "innovative personality" (E. Hagen) entered the language of science. Prigozhin A.I. precisely formulates the content of the innovative personality even before the development of the concept and speaks of the main characteristic of the subject of innovation - "activity self-awareness". The author clearly indicates the need to recognize his "personal initiative as a subjectively possible and socially accepted basis for his own existence" [1], "in the phenomena of innovative behavior ... the process of human self-development declares itself" [2].

Various aspects of the development of innovative potential have been considered and continue to be considered in domestic and foreign psychology and pedagogy.

V.V. Popov reviewed the literature on research in his dissertation research. Innovative activities in the education system were considered in the works of both domestic (I.V. Bestuzhev-Lada, A.I. Prigozhin and others) and foreign (K. Angelovsky, V.N. Potkonyak and others) researchers; specific features of creativity and pedagogical innovation were considered in the works of V.I. Zagvyazinsky, V.A. Kan-Kalik, M.M. Potashnik et al .; professional growth, the formation of a teacher and the development of his creative potential are considered in the works of V.I. Andreev, V.G. Ryndak, A.I. Schetinskaya et al. [3]. We also note that the issues of the teacher's readiness for innovative activities were also considered 
[4]. In general, the problems are well studied at the end of the 20th century.

Understanding the problem of the innovative potential of the university teacher in the situation of time challenges revealed the contradictions between: the objective need to take into account the innovative potential and the insufficient development of this problem in psychological and pedagogical aspects; understanding the importance of using the teacher's innovative potential in the modern educational environment of the university and the insufficient development of tools for studying innovation.

\section{METHODOLOGY}

An analysis of theoretical sources suggests that there are a sufficient number of works on studying the innovative potential of the personality of educators of preschool educational organizations [5], including teachers [4] in institutions of additional education for children [3], while most often there are separate developments on the study of the innovative potential of the personality of a university teacher. Therefore, the relevance of this work is obvious.

The potential of an individual is its resource fund. Under certain conditions, it can be updated and involved to achieve a result. It is important to understand that these conditions must be favorable, as well as individual typological characteristics of the person. V.N. Markov believes that the potential of an individual is a system of its renewable resources, which, in turn, are manifested in activities aimed at obtaining socially significant results [6].

The structure of the potential of an individual is seen in different ways; however, most often its content includes communicative, creative, and moral components. The value-motivational properties of personality are of great importance [7].

Innovation potential is understood as "a combination of personal properties and qualities to create, perceive, implement innovations, and also timely to get rid of outdated inappropriate methods of activity" [8], "as a personal resource that, under appropriate conditions, can manifest itself as a basal basis for initiating innovative behavior "[9].

The position of A. Inkeles is considered to understand the structure of the innovative potential of the individual. The scientist believes that the individual should value education and training at the present stage; personality must be open to experimentation, innovation, and change. It is important for a person to be able to plan his actions to achieve goals, to understand that his point of view is not the only one, and the presence of other positions creates a situation of diversity, and, therefore, choice [10]. These diverse qualities provide the development of intelligence. $\mathrm{He}$ is the controller of the process of formation of innovative potential.
In our opinion, modern man is aimed at self-change, selfexpression through participation in creative activity.

Today, creative abilities, the creative component of innovative potential are becoming a prerequisite for the implementation of teaching activities. This thesis is confirmed by Tomsk scientists who believe that modern socio-economic challenges put a person in a situation where he is forced to reveal his creative potentials, professionalism and erudition [2].

The most significant result of creativity is not only the creation of original, previously non-existent material and ideal objects, but the transformation of the subject of creativity, a change in its inner world. These changes should be manifested in the creative behavior of a person. So, according to A. Belkin, linking creativity with such inseparable categories as activity and imagination, creativity is the basis for the formation of psychosocial personality characteristics [11]. V.N. Druzhinin, in contrast, indicates that activity and creativity are fundamentally different forms of human activity [12].

In our opinion, innovation is directly related to the creative potential of the individual. The ability to be creative in various fields of activity in order to transform existing working methods to increase its efficiency and effectiveness turns new ideas into an innovation that is put into practice and gives an improved result.

In general, innovation is the introduction of new types / methods of activity into various types of human life, the use of various achievements that increase the effectiveness of this activity. Therefore, it is important to form a person who is capable of work and a creative attitude to himself and others, to self-development and personal growth in order to create and further perceive innovations. Thus, there is a need for the formation of the innovative potential of the individual, which is the basis of its development.

So, the innovative potential of a personality is determined by a special set of personal qualities that create the possibility of making non-standard decisions using the available opportunities. One of the important qualities is creativity, which acts as a means of transforming an existing phenomenon with the goal of its unusual, original presentation. This process leads to innovation. The university lecturer uses the innovative potential when creating a training course, choosing methods and teaching aids.

Foreign researchers share interesting experience, who connect innovation potential with systemic changes in the professional development of a teacher as a leader [13], and consider it as a necessary personality characteristic that ensures participation in the joint design of educational innovations [14]; in another case, the category of "selfregulatory learning" is considered, with the help of which the conditions are created so that all students become "self-regulatory", that is, they can take responsibility for their own learning [15].

The problems in the implementation of innovations are also investigated. So, Christie \& Jurado advocate that in 
order to realize the innovative potential of both teachers and students, it is necessary to reasonably combine blended learning and competently approach innovative and high-quality online education [16].

In Estonia, colleagues see e-learning as an innovation. Based on the theory of the spread of innovations by E. Rogers [17], Estonians speak of a significant statistical difference between innovators and other categories among teachers of specialized secondary and vocational higher education institutions in Estonia. The authors of the work point out the fact that among teachers of professional higher education, "a multi-aspect innovative gap arises, covering gaps in the actual use of e-learning tools, various

types of skills and competencies, access and support indicators" [18]. An innovation model is proposed in which competencies are predictors of innovation.

It is important to update creative potential so that the opportunity arises for the formation of innovative potential. It is necessary to make efforts for active creative development, contributing to the formation of innovative potential, which, in turn, leads to efficient production and implementation of innovations.

\section{RESULTS}

Table 1 Diagnostic data for psychological readiness for innovation

\begin{tabular}{|c|c|c|c|c|c|}
\hline Sign & Group & $\mathbf{n}$ & Minimum value & Maximum value & Average \\
\hline \multirow{3}{*}{ Initiative } & 1 & 24 & 7 & 21 & 14 \\
\hline & 2 & 21 & 5 & 19 & 12 \\
\hline & 3 & 19 & 6 & 20 & 13 \\
\hline \multirow{3}{*}{$\begin{array}{l}\text { Preference for activities } \\
\text { requiring innovation }\end{array}$} & 1 & 24 & 5 & 21 & 13 \\
\hline & 2 & 21 & 7 & 21 & 14 \\
\hline & 3 & 19 & 12 & 21 & 16,5 \\
\hline \multirow{3}{*}{$\begin{array}{c}\text { Readiness for change } \\
\text { Initiative }\end{array}$} & 1 & 24 & 8 & 20 & 14 \\
\hline & 2 & 21 & 10 & 20 & 15 \\
\hline & 3 & 19 & 17 & 21 & 19 \\
\hline \multirow{3}{*}{$\begin{array}{c}\text { Psychological readiness for } \\
\text { innovation }\end{array}$} & 1 & 24 & 20 & 61 & 40,5 \\
\hline & 2 & 21 & 22 & 60 & 41 \\
\hline & 3 & 19 & 35 & 62 & 48,5 \\
\hline
\end{tabular}

* Note. Group 1 - teachers with work experience over 20 years; group 2 - teachers with experience from 6 to 10 years; group 3 - young teachers (work experience up to 5 years)

\section{DISCUSSION}

O.M. Krasnoryadtseva believes that the innovative potential of the individual includes the "resource part", which can manifest itself at the behavioral level as a source or prerequisite for self-development [19]. The author obtained data on the psychological readiness for innovative activity of teachers and students in educational institutions of Tomsk and Siberian cities, found 
differences in the indicators of psychological readiness for innovative activity among different groups of participants in the educational process $[19,20]$. Siberian scientists proposed a methodology of "Psychological readiness for innovative activity" (V.E. Klochko, O.M. Krasnoryadtseva), which has wide diagnostic possibilities of application [21].

We planned and proactively carried out a pilot study of the psychological readiness of teachers based on theoretical positions. The base of the study is the educational organizations of Moscow, Krasnoyarsk. A sample of the study was presented by teachers with over 20 years of experience (group 1), $\mathrm{n}=24$; teachers with experience from 6 to 10 years (group 2), $\mathrm{n}=21$; young teachers with an experience of up to 5 years (group 3$) n=$ 19. The total sample size is 64 people.

We give some descriptive statistics in the table. The main research methodology is "Psychological readiness for innovative activity" (V. E. Klochko, O. M. Krasnoryadtseva).

The analysis of the obtained data showed insignificant differences on the scales of the methodology "Psychological readiness for innovation", except for the indicator "readiness for changes", where there are significant differences between groups of young teachers and experienced teachers $(\mathrm{p} \leq 0.004)$. Young teachers who are actively involved in research and project activities have higher indicators of initiative and activities that require innovation and a general level of psychological readiness for innovation than teachers with experience. In addition, there are differences on the basis of "readiness for change" $(\mathrm{p}=0.066)$ in the two study groups.

\section{CONCLUSIONS}

1. The innovative potential of the personality of a university teacher should become a condition for selfdevelopment of the open system of a modern university.

2. It is necessary to approach systematically in the study of innovative potential in order to be aware of its multidimensionality, dependence on age characteristics, individual natural and social living conditions, and to understand how a complex dynamic system in the interaction of a number of elements at different levels.

3 . The innovative potential of the individual in this work was considered as a manifestation of initiative, preference for activities requiring innovativeness, willingness to change, psychological readiness for innovative activities. 4. According to the results of the study, it was found that young teachers have higher innovative potential than teachers with extensive experience.

We want to conclude with a quote from A. Einstein: "Problems can never be solved with the same way of thinking that generated them"; Tomsk scientists V.E. Klochko and O.M. Krasnoryadtseva cite the same quote in his work [20]. Only the innovative potential of a modern university teacher will be able to ensure the acceptance of challenges taking into account the development trend of science.

\section{REFERENCES}

[1] A. I.Prigozhin, Modern sociology of organizations, 1995.

[2] V.Ye. Klochko, E.V. Galazhinsky, Innovative potential of a personality: systemic-anthropological context, Bulletin of Tomsk State University. Series: Psychology and Pedagogy 325 (2009) 146-151.

[3] V.V. Popov, Organizational and pedagogical conditions for the development of innovative potential of a teacher in an institution of additional education for children, Doct, Diss, 2003.

[4] V.A. Slastenin, L.S. Podymova, Pedagogy: Innovation, Publishing House Magister, 1997.

[5] V.N. Kazakova, Management of innovative processes in preschool educational institutions, Doct, Diss, 2000.

[6] A. K. Markov, Modern teacher, 1996.

[7] S.G. Abramova, Theory of innovation, 1999.

[8] O.B. Mikhailova, Methodological foundations of the study of the innovative potential of the individual, University Herald (State University of Management) 21 (2010) 71-75.

[9] E.V. Galazhinsky, V.E. Klochko, O.M.

Krasnoryadtseva, Psychology of innovative activity: thesaurus (a dictionary covering the specifics of professional vocabulary), Tomsk University Press, 2009.

[10] A.M. Inkeles, Management: Organizational behavior, 1999.

[11] A.S. Belkin, The situation of success. How to create it, 1991.

[12] V.N. Druzhinin, An innovative approach to learning, 2001.

[13] D. Frost, From professional development to system change, Teacher leadership and innovation. Professional development in education 38(2) (2012) 205-227.

[14] J. Roschelle, W. Penuel, N. Shechtman, Codesign of innovations with teachers, Definition and 
dynamics, International Society of the Learning Sciences, 2006.

[15] J. Randi, L. Corno, Teacher innovations in self-regulated learning, Handbook of self-regulation, 2000 .

[16] M. Christie, R. Garrote Jurado, Barriers to innovation in online pedagogy, European Journal of Engineering Education 34(3) (2009) 273-279.

[17] E.M. Rogers6 Diffusion of innovations, The Free Press, 1995.

[18] K. Loogma, J. Kruusvall, M. Ümarik, Elearning as innovation, Exploring innovativeness of the VET teachers' community in Estonia, Computers \& Education 58(2) (2012) 808-817.

[19] O.M. Krasnoryadtseva, Psychological readiness for innovative activity of students and teachers as a characteristic of the educational environment, Tomsk State University Bulletin 358 (2012) 152-157.

[20] V.E. Klochko, O.M. Krasnoryadtseva, Actual problems of psychological support of educational project, Development of multidimensional professional thinking of teachers of a research university, TSU Publishing House, 2016.

[21] O.M. Krasnoryadtseva, D.Yu. Balanev, E.A. Scheglova, Diagnostic capabilities of the questionnaire "Psychological readiness for innovative activities", Siberian Psychological Journal 40 (2011) 164-175. 